\title{
Cat scratch disease - a case report
}

Case Report

\author{
Giriyan S.S. ${ }^{1}$, Chandan R.H. ${ }^{2}$, Vyshnavi V. ${ }^{3}$ \\ ${ }^{1}$ Dr. Sujata S. Giriyan, Professor and Head, ${ }^{2}$ Dr. Rajesh H. Chandan, Associate Professor, ${ }^{3}$ Dr. Vasantham vyshnavi, \\ Postgraduate, all authors are attached with Department of Pathology, Karnataka Institute of Medical Sciences, Hubli, \\ Karnataka, India.
}

Corresponding Author: Dr. Vasantham vyshnavi, Department of Pathology, Karnataka Institute of Medical Sciences, Hubli, Karnataka, India. Email: vyshnavivasantham77@gmail.com

\begin{abstract}
Cat scratch disease is benign self-limiting infectious disease caused by B. Henselae. It can occur world-wide with no racial or sex predilection. Cats are the major reservoirs. Transmission can occur through biting, scratching and licking. Patients present with regional lymphadenopathy. A 17-year-old male presented with a single swelling in the inguinal region of 15 days duration. It was gradually increasing in size. The swelling measured $6 \mathrm{~cm} * 5 \mathrm{~cm}$, soft to firm in consistency, non-tender. The mobility was restricted. Fine needle aspiration cytology was performed which was diagnosed as granulomatous lymphadenitis. The swelling was excised and sent for histopathological examination. Histopathologically, a final diagnosis of Cat-scratch lymphadenitis was made. Cat-scratch Disease is a self-limiting illness in an immuno-competent host. The associated lymphadenitis is mainly solitary and unilateral. Although it is not a unique diagnosis, Cat-scratch disease is required to implement appropriate and targeted antibiotic therapy.
\end{abstract}

Key word: Cat scratch disease, Cat scratch disease, cats

\section{Introduction}

Cat-scratch disease (CSD) is a benign infectious disease caused by intra-cellular bacterium Bartonella Henselae. It was first discovered by Henri Perinaud in 1889[1].

Healthy young cats are the main reservoir of the disease-causing bacterium. Dogs, rabbits and monkeys are also reservoirs associated with cat scratch disease apart from cats. The disease peaks in fall and winter [2]. Adults or children $(85 \%$ under age 18$)$ infected by cat claws contaminated with infected flea faeces.

CSD is typically a self-limiting illness consisting primarily of regional lymphadenopathy following approximately 1 to 3 weeks after bite.

\section{Case report}

A 17-year-old male presented with a single swelling in the inguinal region of 15 days duration. It was gradually increasing in size. The swelling measured $6 \mathrm{~cm} * 5 \mathrm{~cm}$, soft to firm in consistency, non-tender.

The mobility was restricted. Fine needle aspiration cytology was performed which showed presence of predominantly histiocytes, lymphocytes and plasma cells along with few epithelioid cell-granulomas.

A diagnosis of Granulomatous lymphadenitis was made.

Later the involved inguinal lymph-node was excised and tissue was sent for histopathological examination.

Gross: Mass was excised measuring $5 \mathrm{~cm} * 3 \mathrm{~cm} * 2 \mathrm{~cm}$. External surface showed few grey white nodules largest measuring $0.5 \mathrm{~cm}$ in diameter. The cut section showed grey-white areas with few areas of haemorrhage.

Manuscript received: $10^{\text {th }}$ April 2018

Reviewed: $20^{\text {th }}$ April 2018

Author Corrected: $28^{\text {th }}$ April 2018

Accepted for Publication: $2^{\text {nd }}$ May 2018 


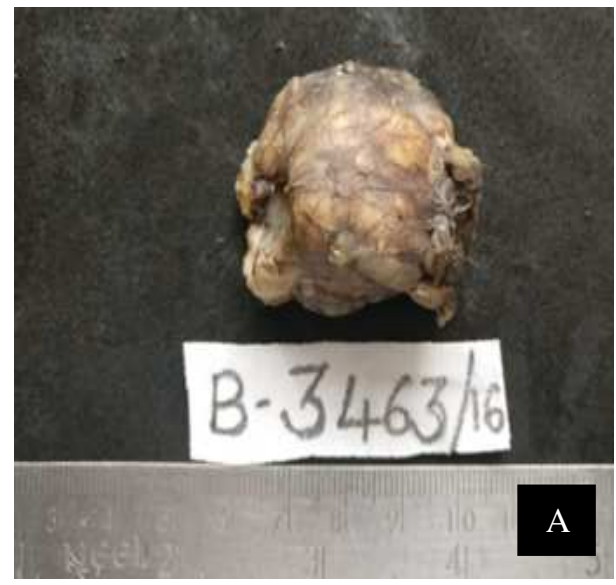

Figure-A: Clinical picture showed globular mass; External surface showed few grey white nodules.

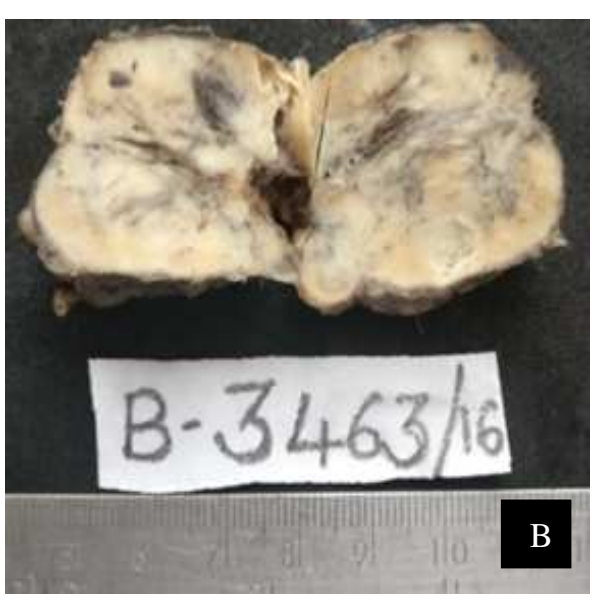

Figure-B: Cut section showed grey-white areas with few areas of haemorrhage.

Microscopy: Structure of lymph-node with effacement and mild distortion of architecture was seen. Sheets and aggregates of histiocytes with proliferating blood vessels and ill-formed granulomas were seen in the cortex. Multiple abscesses were also seen with scattered neutrophils and central eosinophilic necrosis and outer rim of epithelioid cells. A differential of Tuberculosis, Sarcoidosis, Kikuchi's disease and Cat-scratch disease was made.

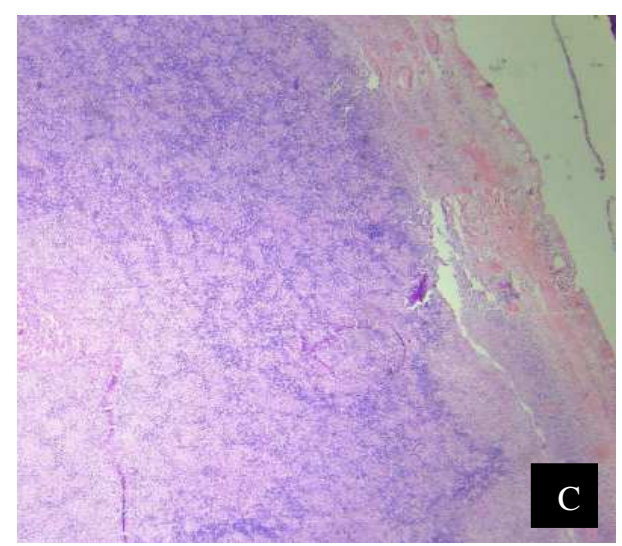

Figure- C: Microscopy showed structure of lymph node architecture with effacement and aggregates of histiocytes. (4x, H \& E stain)

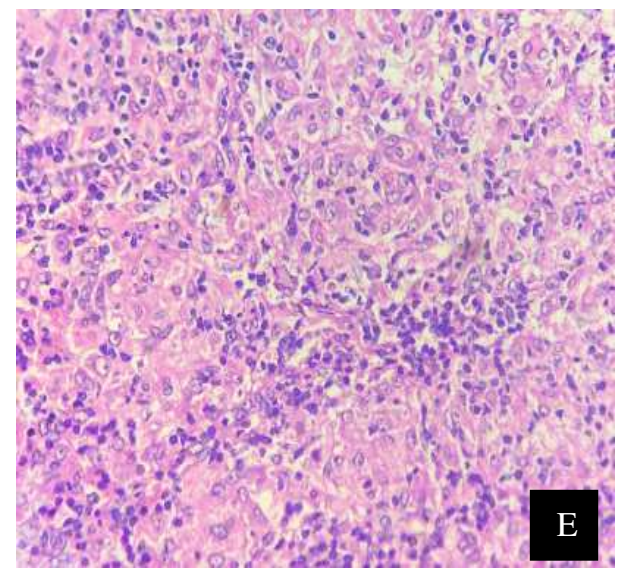

Figure-E: Microscopy showed sheets and aggregates of histiocytes with proliferating blood vessels forming ill-formed granulomas. (40x, H \& E stain)

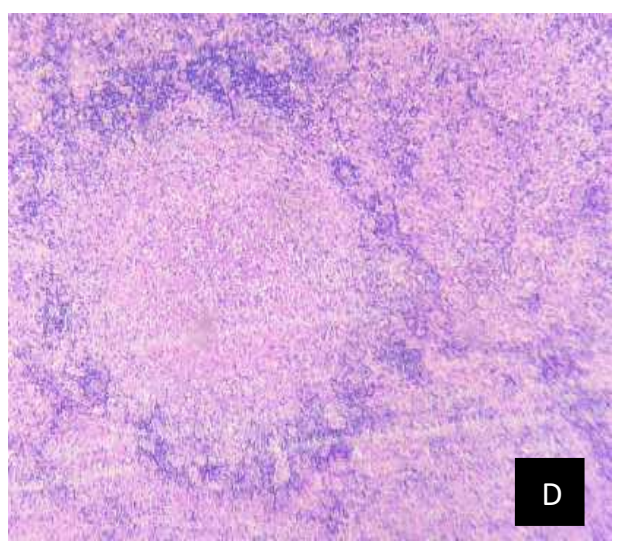

Figure- D:Microscopy showed areas of eosinophilic necrosis. (10x, H \& E stain)

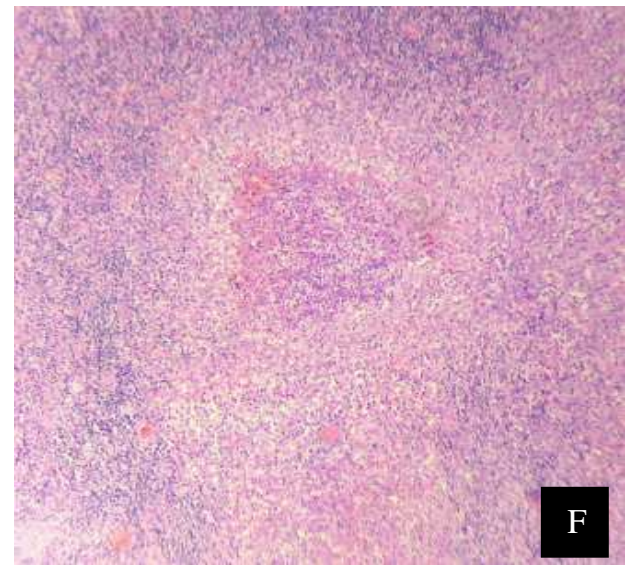

Figure-F: Microscopy showed scattered neutrophils and central necrosis and outer rim of epithelioid cells. (4x, H \& E stain) 


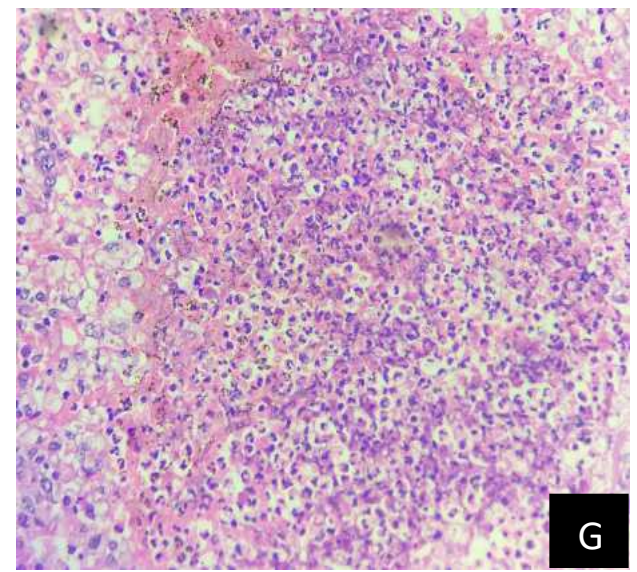

Figure-G: Microscopy showedabscess consisting of neutrophilsandouter rim of epithelioid cells.

(40x, H \& E stain)
Case Report

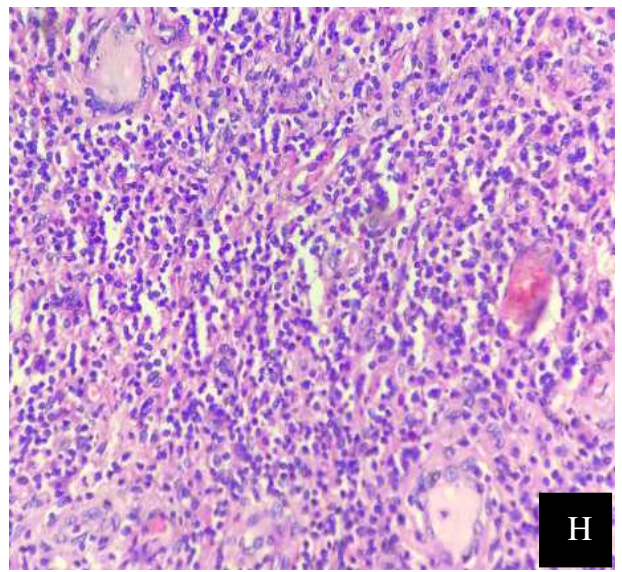

Figure-H: Microscopy showed foci of gaint cells, Lymphocytes and aggregates of epitheloid cells. (40x, H \& E stain)

Zeihl-Neelson staining was performed which was negative for Acid fast bacilli. Gomori's methane amine silver stain was performed which revealed presence of rod shaped and L-shaped bacilli in singles, within the areas of necrosis and near proliferating vessels. These were suspected to be Bartonella Henselae.

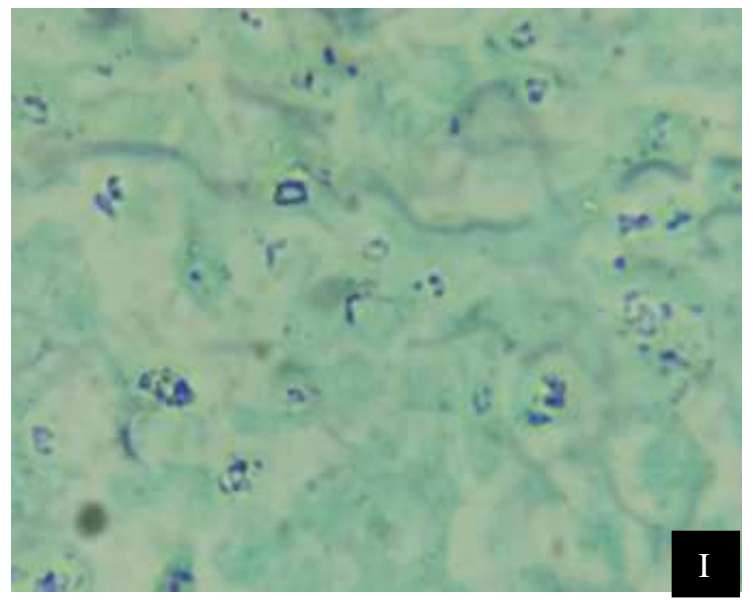

Figure-I: Microscopy showed presence of rod shaped and L-shaped bacilli in singles and clumps. (100x oil immersion, GMS stain)

A final diagnosis of Cat-scratch lymphadenitis was made.

\section{Discussion}

Cat-scratch disease (CSD) is a common cause of chronic lymphadenopathy among children and adolescents, and the major etiologic agent underlying it is the bacterium Bartonella Henselae [3,4]. Incidence of CSD was highest among those who lived in the southern United States (6.4 cases/100,000 population) and among children 5-9 years of age (9.4 cases/100,000 population)[5]. Pathogens are transmitted by bites or scratches from infected cats.

These bacterial pathogens are gram negative, pleomorphic small rods occurring in singles or in clumps [6]. They are seen within the foci of necrosis, vessel walls and in the vicinity of collagen fibres. The bacilli are best stained Warthin-Starry silver impregnation stain [6,7]. The major criteria for diagnosis of CSD have been exposure to cat bite or scratch, an inoculation site, regional lymphadenopathy, typical histopathology on lymph node biopsy, negative tests for other infections, and a positive delayed hypersensitivity skin test using CSD antigen.

Most of the patients presents with erythematous patch in affected area, this is followed by a papular and then a vesicular lesion which oozes fluid. The lesion then dries to form a scab. Usually a unilateral lymphadenitis near 
the scratch, bite site develops 2-3 weeks after infection, which is usually in the head, neck, axilla, or supraclavicular region. Atypical manifestations include mammary, oculo-glandular, hepatosplenic, cardiopulmonary, central nervous system, and bone involvement.

The present case also came with unilateral and single palpable inguinal lymph node [8]. Cat-scratch lymphadenopathy is characterized by enlarged and matted lymph nodes which are usually adherent to the surrounding soft tissues [8,9]. This may be the cause of restricted mobility as seen in the present case.

On gross examination, the lymph node is enlarged with multiple abscesses over the surface, appearing as small nodules. This type of picture was seen in the case under study also.

These whitish nodules correspond to the microabscesses which coalesce and extend under the capsule of the affected lymph-node.

Microscopically there is reactive follicular hyperplasiain the earlystages of the disease, followed by the development of the granulomas. There is increase in the macrophage activity, vascular proliferation and increases in monocytoid population of cells $[9,10]$

Present case showed similar features with proliferation of mainly histiocytes and granuloma formation. Cortex of the lymph node characterized by exudation of polymorphonuclear leukocytes with central micro abscessesformation and foci of necrosis.

These abscesses coalesce and form large areas of necrosis, surrounded by neutrophils, band of epithelioid cells palisading and fibrinous material $[8,10]$. Present case showed focal necrotic areas surrounded by rim of epithelioid cells and also presence of ill-formed granulomas.

B. Henselae is a gram-negative bacterium, but this organism does not readily stain with a Gram stain.

Traditionally, silver impregnation stains such as Warthin-Starry or Steiner stains have been used to aid in the microscopic identification of B. Henselae organisms, which appear as pleomorphic bacilli in clumps or as single forms [10,11,12].

In present case we used GMS stain, bacilli were present within the foci of necrosis and walls of proliferating vessels.

\section{Conclusion}

Cat-scratch Disease is a self-limiting illness in an immuno-competent host. The associated lymphadenitis is mainly solitary and unilateral. Identification of Catscratch lymphadenitis would be quite difficult. However, in immune-compromised individuals it might lead to systemic involvement of other organs.

Although it is not a unique diagnosis, precision in labelling it as Cat-scratch disease is required to extract history of animal contacts, proper intervention for diagnosis and implement appropriate and targeted antibiotic therapy.

\section{Funding: Nil, Conflict of interest: None initiated Permission from IRB: Yes}

\section{References}

1. Jerris RC, Regnery RL. Will the real agent of catscratch disease please stand up? Annu Rev Microbiol. 1996;50:707-25.

2. Bass JW, Vincent JM, Person DA. The expanding spectrum of Bartonella infections: II. Cat-scratch disease. Pediatr Infect Dis J. 1997 Feb;16 (2): 163-79.

3. Dolan MJ, Wong MT, Regnery RL, Jorgensen JH, Garcia M, Peters J, Drehner D. Syndrome of Rochalimaeahenselae adenitis suggesting cat scratch disease. Ann Intern Med. 1993 Mar 1;118(5):331-6.

4. Anderson B, Sims K, Regnery R, Robinson L, Schmidt MJ, Goral S, Hager C, Edwards K. Detection of Rochalimaeahenselae DNA in specimens from cat scratch disease patients by PCR. J Clin Microbiol. 1994 Apr;32(4):942-8.

5. Nelson, C. A., Saha, S., \& Mead, P. S. (2016). CatScratch Disease in the United States, 2005-2013. Emerging Infectious Diseases, 22(10), 1741-1746. doi: 10.3201/eid2210.160115.

6. Wear DJ, Margileth AM, Hadfield TL, Fischer GW, Schlagel CJ, King FM. Cat scratch disease: a bacterial infection. Science. 1983 Sep 30;221(4618):1403-5.

7. Margileth AM. Cat-scratch disease: non-bacterial regional lymphadenitis. The study of 145 patients and review of literature. Pediatrics1968;42:803-18. (DOI: 10.1111/j.1834-7819.1985.tb05830.x)

8. WINSHIP T. Pathologic changes in so-called catscratch fever; review of findings in lymph node of 29 patients and cutaneous lesions of 2 patients. Am J Clin Pathol. 1953 Oct;23(10):1012-8. 
9. Carithers HA. Cat-scratch disease. An overview based on a study of 1,200 patients. Am J Dis Child. 1985 Nov;139(11):1124-33.

10. Miller-Catchpole R, Variakojis D, Vardiman JW, Loew JM, Carter J. Cat scratch disease. Identification of bacteria in seven cases of lymphadenitis. Am J SurgPathol. 1986 Apr;10(4):276-81.

\section{Case Report}

11. Cotter B, Maurer R, Hedinger C. Cat scratch disease:evidence for a bacterial etiology: a retrospective analysis using the Warthin-Starry stain. Virchows Arch A Pathol Anat Histopathol. 1986; 410 (2): 103-106.

12. KorbiS, Toccanier MF, Leyvraz G, Stalder J, Kapanci Y. Use of silver staining (dieterlé'sstain) in the diagnosis ofcat scratch disease. Histopathology. 1986 Oct; 10 (10): 1015-21.

\section{How to cite this article?}

Giriyan S.S, Chandan R.H, Vyshnavi V. Cat scratch disease- a case report. Trop J Path Micro 2018;4(2):167-171. doi: 10.17511/jopm.2018.i2.09 